\title{
Modeling water column structure and suspended particulate matter on the Middle Atlantic continental shelf during the passages of Hurricanes Edouard and Hortense
}

\author{
by Alejandro J. Souza ${ }^{1}$, Tommy D. Dickey ${ }^{2}$ and Grace C. Chang ${ }^{2}$
}

\begin{abstract}
The present contribution is motivated by the desire to elucidate the processes that contributed to the evolution of observed thermal structure and resuspension of particulate matter during and after the passages of two hurricanes, Edouard and Hortense, within a two-week period in late-summer 1996. A unique set of high temporal frequency measurements of the vertical structures of physical and optical properties was obtained at a mooring site near the Middle Atlantic Bight continental shelf-break (70 $\mathrm{m}$ water depth). These data provided insight and initial conditions for the physical model used for this study. The model accounted for wind and bottom current generated turbulence, surface waves, wave-current interactions, tides, and depth-dependent density-driven circulation. We find that the most important process controlling the thermal water column structure during and following the passage of Hurricane Edouard was the wind stirring. Differences between the model results and the observations of thermal structure may have been caused by advection, which is not included in this one-dimensional model. There is also clear evidence of internal tides in the observations, whereas the model could not reproduce this effect. A suspended particulate matter (SPM) model is included as a module of the physical model to examine sediment resuspension processes. It is concluded that wave-current bottom shear stress was clearly the most important process for sediment resuspension during and following both hurricanes. Discrepancies between modeled and observed SPM are attributed to the presence of biological material in the surface waters and changes in sediment properties (flocculation and de-flocculation) during and following the passages of the hurricanes.
\end{abstract}

\section{Introduction}

The physics and distribution of suspended particulate matter (SPM) on continental shelves are important for several relevant societal problems. These include: primary production, upper and benthic layer ecology, biogeochemical cycling, carbon fluxes, optical property variability, pollutant resuspension and transport, and water quality in general (e.g., Eisma, 1990; Tett et al., 1993). The coastal ocean's shelf domain is highly dynamic and complex, which results in variability on short as well as longer time and space

1. Proudman Oceanographic Laboratory, Bidston Observatory, Bidston Hill, Prenton CH43 7RA, United Kingdom,email:ajso@pol.ac.uk

2. Ocean Physics Laboratory, University of California, 6487 Calle Real/Unit A, Santa Barbara, California, 93117, U.S.A. 
scales. For example, water column thermal structure and stratification are often controlled to first order by the competition of the stratifying influence of solar radiation and mixing caused by winds and tides (e.g., Simpson and Bowers, 1981). The Middle Atlantic Bight (MAB) region of the present study is also affected by dynamics of surface and bottom boundary layers, large-scale buoyancy-driven coastal currents, slope water intrusions, tides, internal tides, surface and internal gravity waves, and internal solitary waves (e.g., see Backus, 1987; Dickey and Williams, 2001, and references therein). These same physical processes are important, to varying degrees, for sediment resuspension and/or transport (e.g., Agrawal and Traykovski, 2001; Chang et al., 2001; Hill et al., 2001). As a coarse generalization, the vertical flux of SPM can be considered to be dependent upon bed shear stress (caused by waves, currents, and the interaction between waves and currents), vertical mixing (turbulent diffusion), and particle settling under gravity (e.g., Jones et al., 1996). However, there can also be complex interactions among several other physical, geological, and biological processes via organisms and particles (especially cohesive particles), which can modify the particulates and their particle size distributions and setting velocities (e.g., Lick et al., 1993; McNeil et al., 1996; Hill et al., 2001).

The present work concerns unique observations, namely the response of the vertical structure of hydrographic properties and SPM on a coastal ocean shelf to the passages of two hurricanes within a two-week period. Fortuitously, Hurricanes Edouard and Hortense passed through a region of intensive ocean sampling (Coastal Mixing and Optics (CMO) program, Dickey and Williams, 2001) in the MAB devoted to the observation of physical and optical processes in both the water column and near the ocean bottom with sampling on scales of minutes to one year. Preliminary descriptions and analyses of the relevant time series have been presented by Dickey et al. (1998), Chang and Dickey (2001), and Chang et al. (2001). The present contribution builds on these earlier efforts and is designed to elucidate the processes that contributed to the evolution of the observed hydrographic structure and resuspension of particulate matter during and after the passages of the hurricanes.

The key goals of the present study are to: (1) test the hypothesis that the sediment resuspension observed during the passage of Hurricanes Edouard and Hortense was due to bottom wave-current interaction (Chang et al., 2001); (2) evaluate the efficacy of the one-dimensional model for simulating the evolution of thermal structure and sediment resuspension in the wakes of two hurricanes; and (3) identify discrepancies between model results and observations in order to suggest processes and parameterizations that may be important for future observational programs and model formulations. In particular, it is anticipated that future models will incorporate three-dimensional dynamics. It will remain critical to employ the best possible modeling formulations for the vertical dimension, and thus the present modeling exercise should prove valuable. A short summary of the relevant observations is presented for completeness. The hydrodynamical and sediment resuspension models are described briefly; Appendix II provides details of the model formulations. 


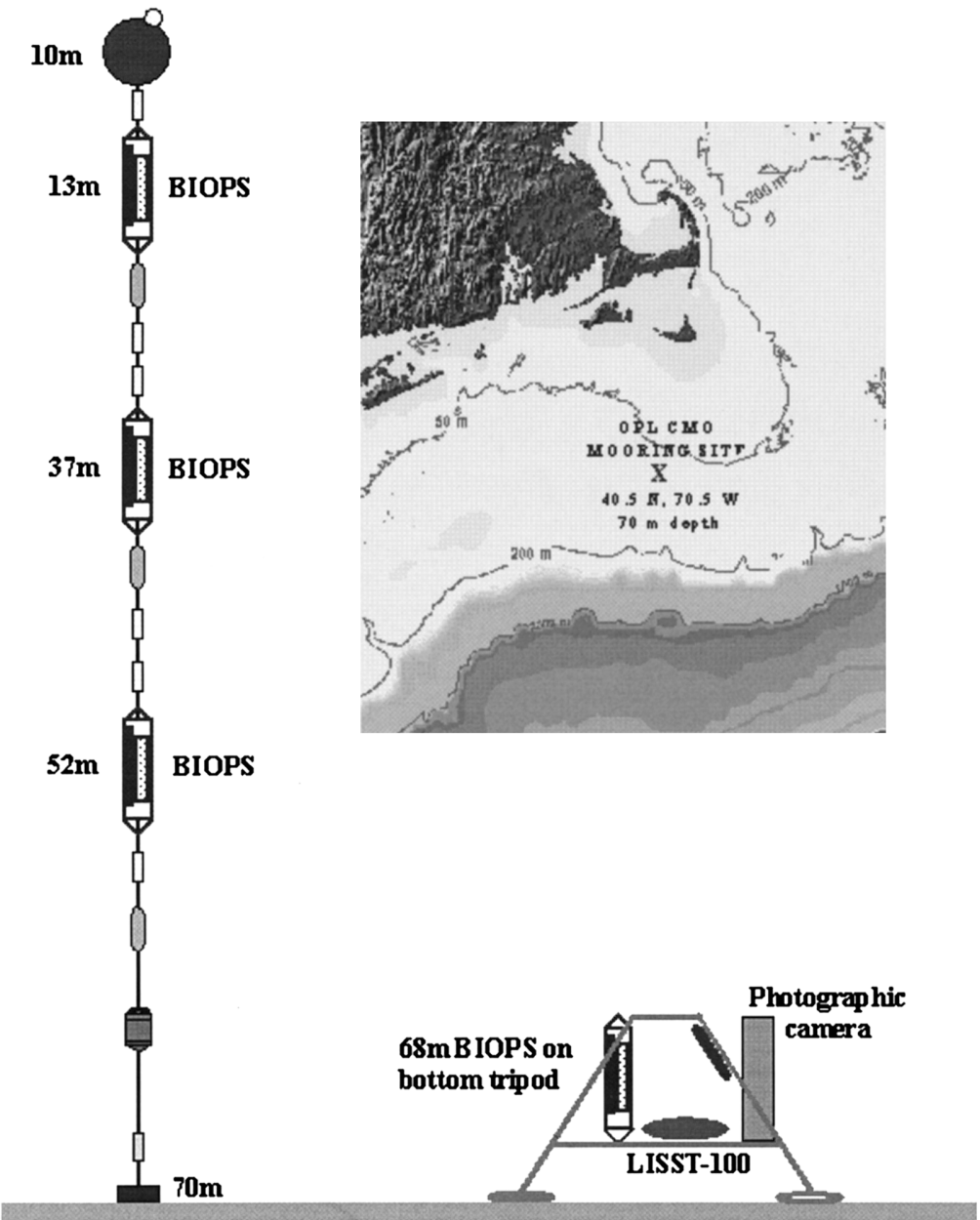

Figure 1. Geographic location of the Coastal Mixing and Optics mooring site (X) and a schematic diagram of the mooring and tripod.

The model and case study simulations are then discussed. Finally, a summary and conclusions are presented.

\section{Observations}

The CMO field study was conducted in a region known as the "Mud Patch" in the MAB and located about $110 \mathrm{~km}$ south of Martha's Vineyard, Cape Cod, Massachusetts, U.S.A. (Fig. 1). The Mud Patch is a sediment deposit of 3 to $14 \mathrm{~m}$ thickness covering an area of about $100 \mathrm{~km}$ by $200 \mathrm{~km}$ and is composed of relatively uniform fine-grained material that overlies coarser sand-size sediment (Twichell et al., 1987). The mean and tidal currents in 
the area typically have amplitudes on the order of $10 \mathrm{~cm} \mathrm{~s}^{-1}$, with $M_{2}$, and to a lesser extent $O_{1}$, being the principal tidal constituents (Brink et al., 1987; Brown and Moody, 1987; Twichell et al., 1987; Chang and Dickey, 2001). Subtidal currents generally flow from east to west, following bathymetry. Near-bottom current velocities are roughly half of those at the surface (Twichell et al., 1987).

An overview of the CMO study objectives, observations, locations of sampling platforms, timelines of sampling, and references to other CMO papers are provided in Dickey and Williams (2001). The observations presented here (see Chang et al., 2001) were collected during the first CMO mooring deployment, focusing on the period of 17 August to 19 September 1996 (year day (YD) 230 to 263; hereafter year days are used). The mooring and bottom tripod, which provided most of the data for this study, were located at approximately $40.5 \mathrm{~N}, 70.5 \mathrm{~W}$ in $70 \mathrm{~m}$ of water (Fig. 1). Several physical and optical parameters including currents, temperature, and beam attenuation coefficient $(676 \mathrm{~nm}$; hereafter called beam c; used as a measure of turbidity) were measured using moored bio-optical systems (BIOPS) packages at 13, 37, and $52 \mathrm{~m}$ depths. A BIOPS package was also mounted on a bottom tripod at $\sim 1.5 \mathrm{~m}$ above the seafloor ( $68 \mathrm{~m}$ depth). A continuous wave record was obtained by combining the data from a Seatex waverider buoy from 00:00 hours on 17 August 1996 to 22:00 hours on 4 September 1996 (deployed at 40.49N, $70.50 \mathrm{~W}$, about $1 \mathrm{~km}$ from the mooring; Galbraith et al., 1999) and wave parameters from National Data Buoy Center (NDBC) buoy 44008 from 23:00 hours on 4 September 1996 to 23:00 hours on 19 September 1996 (located at 40.50N, 69.42W, about $90 \mathrm{~km}$ east of the CMO site). Surface water temperature and winds were obtained from a buoy located at $40.49 \mathrm{~N}, 70.50 \mathrm{~W}$; anemometer height was about $3 \mathrm{~m}$ above the sea surface (data provided by S. Lentz and S. Anderson from Woods Hole Oceanographic Institution).

Time series of winds, significant wave height, temperature at five depths, and beam $c$ at $68 \mathrm{~m}$ are shown in Figure 2a-d for the period of YD 230 to 263 and depict some of the key forcing and response variables. The observed wind (by component and speed; Fig. 2a) time series reflects the passages of several moderate-scale weather systems with peak wind speeds typically less than $10 \mathrm{~m} \mathrm{~s}^{-1}$. However, the dominant feature is the intense wind event associated with Hurricane Edouard that was centered around YD 246 when the eye of the hurricane was about $110 \mathrm{~km}$ to the east of the mooring site. The wind vectors are consistent with the northward movement of a strong low-pressure system (clockwise wind rotation) to the east of the mooring site. Peak winds at the site reached $20 \mathrm{~m} \mathrm{~s}^{-1}$. Note that the hurricane-related winds were first directed toward the southwest (YD 245; implied Ekman transport roughly toward the coast) and later toward the east (YD 247; implied Ekman transport to the south and off the shelf; effectively upwelling favorable). The observed current structure is consistent with the inferred Ekman transport (see Chang and Dickey, 2001). Current velocities in the upper water column increased from $\sim 20 \mathrm{~cm} \mathrm{~s}^{-1}$ to greater than $65 \mathrm{~cm} \mathrm{~s}^{-1}$ during the passage of Hurricane Edouard. Hurricane Hortense resulted in weaker subtidal currents with variable flow directions. Interestingly, the wind 

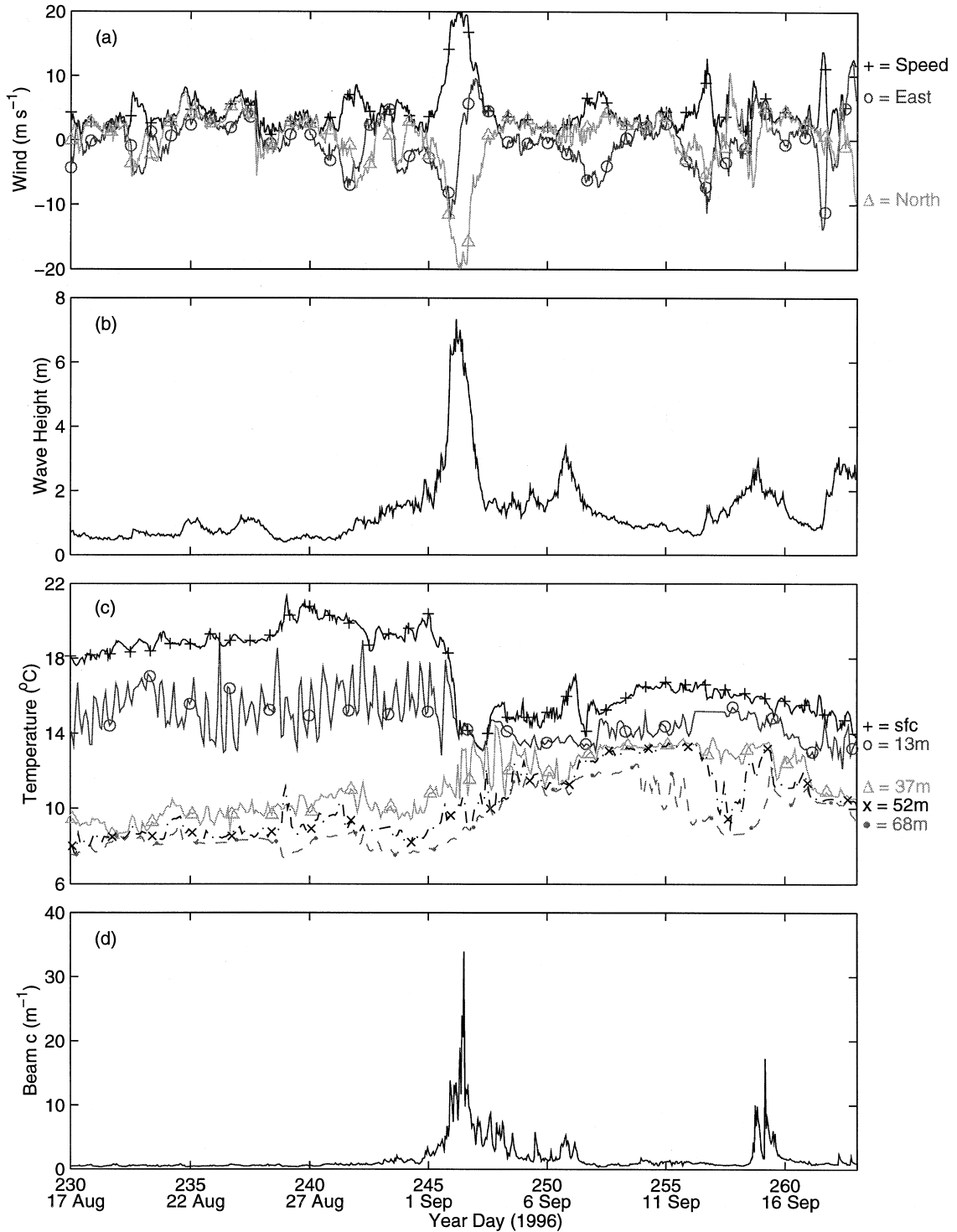

Figure 2. Time series observations of (a) wind velocity, (crosses) speed, (open circles) east-west component, and (triangles) north-south component; (b) significant wave height; (c) temperature at (crosses) the surface, (open circles) $13 \mathrm{~m}$, (triangles) $37 \mathrm{~m}$, (X's) $52 \mathrm{~m}$, and (closed circles) $68 \mathrm{~m}$; and $(\mathrm{d})$ beam attenuation $(676 \mathrm{~nm})$ at $68 \mathrm{~m}$.

effects of Hurricane Hortense, whose closest passage was on YD 258 and about $350 \mathrm{~km}$ away (to the east), are not particularly evident in the time series.

The time series of the significant wave height (Fig. 2b) shows increasing values a few 
days prior to the peak winds of Hurricane Edouard at the CMO site, likely due to the arrival of swell associated with faster moving, long wavelength, surface gravity waves. However, the peak wave heights, which reached about $7.5 \mathrm{~m}$, are very nearly coincident with the peak local wind speeds. This near coincidence suggests concurrent intense local wind mixing and wave stress on the ocean bottom. There are secondary wave height peaks slightly in excess of $2.5 \mathrm{~m}$ on approximately YD 251, 259, and 263. These are qualitatively correlated with local peaks in winds. The peak significant wave height on YD 259 was related to the more distant Hurricane Hortense.

The vertical structure of density (stratification) was primarily controlled by temperature at the mooring site with surface to bottom salinity differences of less than $0.5 \mathrm{psu}$ (based on nearby CTD profile data obtained by W.S. Pegau and E. Boss from Oregon State University). Time series of temperature for the period YD 230-263 are shown for the surface and depths of 13, 37, 52, and $68 \mathrm{~m}$ (progressing from top to bottom) in Figure 2c. The upper $37 \mathrm{~m}$ were strongly stratified until approximately YD 246 when Hurricane Edouard passed by the CMO site. Up to this time, diurnal cycling (amplitude is generally $<1^{\circ} \mathrm{C}$ ) of surface temperature was evident and frequency autospectra reveal that the large oscillations in the $13 \mathrm{~m}$ time series were due to strong semi-diurnal internal tides. With the passage of Edouard, the upper layer was then mixed downward to roughly $37 \mathrm{~m}$ and deeper waters were entrained causing decreased upper layer temperature by about $7^{\circ} \mathrm{C}$. The bottom layer remained stratified until Edouard's arrival. At this point, the bottom layer warmed significantly (by about 3 to $4^{\circ} \mathrm{C}$ ) suggesting downward mixing of warmer waters from the upper layer. We speculate that the bottom temperatures also increased through advection of warm waters from the inner shelf; this advection may have been induced by strong downwelling favorable winds. Current meter data corroborate this hypothesis (see Chang and Dickey, 2001), with currents flowing onshore $\left(\sim 65 \mathrm{~cm} \mathrm{~s}^{-1}\right)$ in the upper $40 \mathrm{~m}$ and offshore below $40 \mathrm{~m}\left(\sim 20 \mathrm{~cm} \mathrm{~s}^{-1}\right)$ starting on YD 245 . Downwelling favorable conditions lasted for $\sim 2$ days. There were also interesting transient oscillations of temperature at $37 \mathrm{~m}$ and to a lesser degree at $52 \mathrm{~m}$ following the passage of Hurricane Edouard. Frequency autospectra analyses indicate that these may have been short-lived inertial oscillations. The surface mixed layer appears to have briefly deepened to greater than $60 \mathrm{~m}$ (using supporting mooring temperature data and a $1^{\circ}$ temperature criterion; Chang et al., 2001). The top to bottom temperature difference decreased from a value of about $13^{\circ} \mathrm{C}$ on YD 230 (day of closest approach of Hurricane Edouard) to about $4^{\circ} \mathrm{C}$ for the period of YD 248 to 253; thus, the thermocline became much less intense as a result of the mixing. The water column began to re-stratify about 6-7 days following the passage of Edouard (YD 252). The upper layer (surface to $13 \mathrm{~m}$ ) temperatures were variable following Hurricane Edouard, but no major changes were evident aside from an apparent wind mixing event that caused the mixed layer to reach at least $13 \mathrm{~m}$ on YD 257. On the other hand, the bottom layer (from 37 to $68 \mathrm{~m}$ ) showed significant variability, first when temperature decreased by about $5^{\circ} \mathrm{C}$ at $68 \mathrm{~m}$ beginning on YD 254 and then by about $4^{\circ} \mathrm{C}$ at $52 \mathrm{~m}$ beginning on YD 257. Temperatures at both depths then increased by $\sim 3^{\circ} \mathrm{C}$ within 
two days, most likely due to Hortense wind-induced mixing of the water column beginning on YD 259. Mixed layer depths increased from $\sim 18 \mathrm{~m}$ to $\sim 50 \mathrm{~m}$ following Hortense (Chang et al., 2001).

Beam $c$ values at $68 \mathrm{~m}$ depth $(\sim 2 \mathrm{~m}$ above the ocean bottom; used as a measure of turbidity) exceeded $30 \mathrm{~m}^{-1}$ (average values were $\sim 1 \mathrm{~m}^{-1}$ for the deployment period prior to the passages of the hurricanes) during Hurricane Edouard (roughly YD 246) and $15 \mathrm{~m}^{-1}$ during Hortense (around YD 259; Fig. 2d). The time series of significant wave height was well correlated with the beam $c$ time series for most of the record. Again, the peak winds of Hurricane Edouard also matched the sediment beam $c$ peak period. However, other periods did not appear to exhibit strong wind-beam $c$ correlation.

The final observational time series description concerns SPM concentration. Time series of SPM were calculated using BIOPS beam $c$ data at 3 depths: 37, 52 and $68 \mathrm{~m}$ (Fig. 3; equations are presented in Appendix I; $13 \mathrm{~m}$ beam $\mathrm{c}$ data were not valid because of biofouling and, therefore, not useful during the period of hurricane passages). As discussed above, the resuspension near the bottom $(68 \mathrm{~m})$ was highly correlated with the significant wave height. This also appears to be the case for depths of 52 and $37 \mathrm{~m}$ with the main difference being time lags between the $37 \mathrm{~m}, 52 \mathrm{~m}$ and $68 \mathrm{~m}$ SPM maxima (half-day for Edouard and three-quarters of a day for Hortense). Some possible reasons for these lags are discussed in the Model Results and Sensitivity Simulations section.

The causal relationships between wind and wave forcing and temperature structure and sediment resuspension required further examination. Thus, a set of numerical model simulations was executed and analyzed.

\section{The model}

The model presented here is designed to examine the processes that contributed to the evolution of the observed thermal structure and resuspension of particulate matter during and after the passages of Hurricanes Edouard and Hortense. A complete characterization and quantification of the observations would require a three-dimensional data set; however, bio-optical data were collected from a single site during our field study. Therefore, the present work utilizes a one-dimensional modeling approach to study processes that are hypothesized to explain the observed physical and sediment variability to first order.

Detailed descriptions of the physical and SPM model components and their coupling are provided in Appendix II. Therefore, only a brief summary is provided here. The onedimensional hydrodynamical model used for the study is similar to one described by Souza and Simpson (1997). The model includes primitive equations for momentum. Neither horizontal nor vertical advection (e.g., terms such as $u * \partial u / \partial x, v * \partial u / \partial y$, etc.) is explicitly included in the momentum equations. However, the horizontal pressure gradient is formulated to include effects of tidal slopes and depth-invariant horizontal density gradients (setting up mean surface slope) driving a depth-dependent density circulation. Horizontal advection of heat (temperature) was included in the heat budget equation. The horizontal gradient for temperature was calculated using CTD observations collected near 

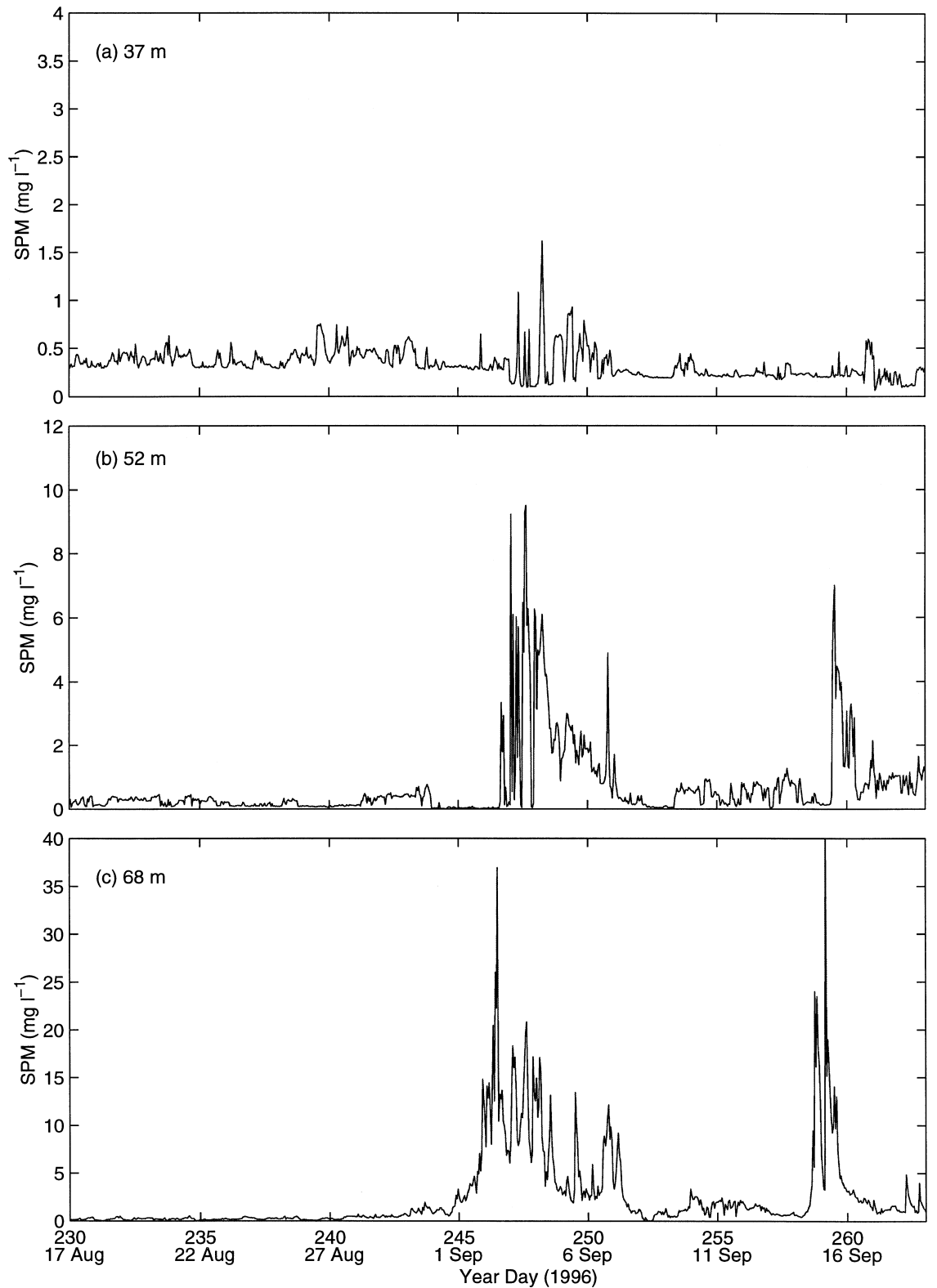

Figure 3. Suspended particulate matter derived from beam attenuation data at (a) $37 \mathrm{~m}$, (b) $52 \mathrm{~m}$, and (c) $68 \mathrm{~m}$.

the mooring on YD 230 and 231 (17 and 18 August 1996), while the model calculated the horizontal velocity. The well-known Mellor-Yamada level 2.5 turbulence closure scheme was used for the parameterization of turbulent mixing (Mellor and Yamada, 1974). The 
surface stress and heat fluxes were computed using standard bulk formulae and local meteorological data sets. It was assumed that $55 \%$ of the short-wave solar radiation is absorbed in the first layer and the rest is distributed exponentially with depth. This distribution is typical of the absorption of solar radiation in coastal waters (Simpson and Bowers, 1984). Bottom boundary conditions for momentum account for wave-current interaction; wave data were used in the computations of wave-induced bottom stress. Model simulations were initialized using temperature and salinity (T-S) data from a CTD cast taken near the mooring on YD 230. The model is run for 5 days to allow tidal and inertial currents and the vertical profile of turbulence to stabilise. Then, it is reinitialized using the original T-S profile and is forced with the appropriate tidal and meteorological forcing. The vertical grid spacing and time step for the model are $2 \mathrm{~m}$ and 2 seconds, respectively, which is within the stability condition (see Appendix II).

The SPM model is similar to one developed by Jones et al. (1996). The model uses a generalized diffusion-deposition equation for the concentration of two classes of particles. The two classes have settling velocities of 0.5 and $0.005 \mathrm{~cm} \mathrm{~s}^{-1}$, corresponding to silt and fine sand, which describe the majority of particles in the Mud Patch. Settling velocities of flocculated and de-flocculated cohesive particles present in the Mud Patch are difficult to characterize, which may lead to inconsistencies between observations and model results (discussed below). The model utilizes the vertical eddy diffusivity coefficient (i.e., computed for temperature) computed using the turbulence closure scheme for the vertical eddy diffusivity of particle concentrations (for each of the two size classes; Jones et al., 1996). A zero vertical particle flux is applied as a surface boundary condition whereas a formulation for the bottom particle flux condition includes terms for particle settling, vertical diffusion, entrainment rate, and a deposition velocity taken to be equivalent to the settling velocity (Lavelle et al., 1984).

\section{Model results and sensitivity simulations}

A series of model simulations (Cases I, II, III, and IV) was conducted in order to determine the relative importance of the different processes and forcing mechanisms (e.g., surface heating, winds, tides, waves, horizontal temperature gradient, etc.) that contributed to the evolution of the vertical temperature structure and sediment resuspension. The first simulation, Case I, includes all of the processes that were incorporated in the model as outlined in Appendix II. Case I is examined in the most detail (see below). Note that bottom stress was calculated in two separate ways: (1) using a constant drag coefficient as explained in Appendix II (applied for Cases II and IV) and (2) using a formulation including wave-current interaction for the bottom stress (applied for Cases I and III). A summary of the four cases follows:

Case I: Includes surface heating, winds, tides, wave-current interaction in bottom stress, and the advection/horizontal temperature gradient effect $(\partial T / \partial y=8 \times$ $10^{-5}{ }^{\circ} \mathrm{C} \mathrm{m}^{-1}$ ) 
Case II: Includes only surface heating, winds, and tides.

Case III: Includes Case II forcing plus wave-current interaction in bottom stress.

Case IV: Includes Case II forcing plus the advection/horizontal temperature gradient effect.

Case I is the most realistic case study as it includes provisions for a complete set of processes. Temperature time series results for Case I forcing are shown for the surface, 13, 37, 52, and $68 \mathrm{~m}$ in Figure $4 \mathrm{a}$ for the observations and Figure $4 \mathrm{~b}$ for the model. The simulated temperatures are generally in good agreement with the observations. The surface temperature started at about $18^{\circ} \mathrm{C}$ and increased gradually for about two weeks. Then, the observed and modeled surface temperature and the temperature at $13 \mathrm{~m}$ decreased sharply by about 6 and $4{ }^{\circ} \mathrm{C}$, respectively, in response to the passage of Hurricane Edouard on YD 246. At that time, there are also increases in observed and modeled temperature at $37 \mathrm{~m}$, suggesting strong mixing effects in both the surface and bottom layers. After the passage of Edouard, the observed and modeled surface temperatures gradually increased for about 10 days and then steadily decreased. A discrepancy between the two sets of time series is evident with the observed values exceeding the model values by roughly $2^{\circ} \mathrm{C}$ at the surface and $13 \mathrm{~m}$ after Edouard passed. The observed and modeled $37 \mathrm{~m}$ and $52 \mathrm{~m}$ time series are in relatively good agreement. Note that the $68 \mathrm{~m}$ modeled time series essentially overlaps the $52 \mathrm{~m}$ modeled time series, as the initial temperatures at these two depths were nearly the same. Following the passage of Edouard, it is likely that mean advection of heat (temperature) became important, especially at depths of 52 and $68 \mathrm{~m}$ and contributed to the disparities in modeled and observed temperatures. The other significant difference between the model results and observations is the strength of the semi-diurnal variability at $13 \mathrm{~m}$ prior to Edouard's passage and afterward at $37 \mathrm{~m}$. This is due to the fact that the model is one-dimensional, and thus cannot account for internal tides and waves. Semi-diurnal effects that can be reproduced in one dimension are tidal advection and tidal straining. Despite the lack of advection in the momentum equation and internal tides and waves in the model, these results indicate that the physics incorporated in our model are adequate to capture the major mixing and thermodynamical processes observed during the passages of Hurricanes Edouard and Hortense.

The Case I model simulations of SPM (Fig. 5) are in qualitative agreement with the observations (Fig. 3). Maximum simulated values of SPM occurred on days 246 and 259 when the waves generated by Hurricane Edouard and Hurricane Hortense were strongest at the CMO mooring site. There is also a significant peak in both simulations and observations of SPM on about YD 251 at $52 \mathrm{~m}$. Note that the peak is also evident at 37 and $52 \mathrm{~m}$ in the simulation, but not in the observations. Also, there is an apparent lag of about half a day between the peaks in observed SPM at 68, 52, and $37 \mathrm{~m}$ during Edouard and of about three quarters of a day between peaks during Hortense. However, there appears to be little if any analogous lag for the simulations. This could be due to the fact that the model includes only two constant setting velocities. Moreover, it does not account for the break up of flocculates, which would result in slower rates of settling and also allow for greater effects 

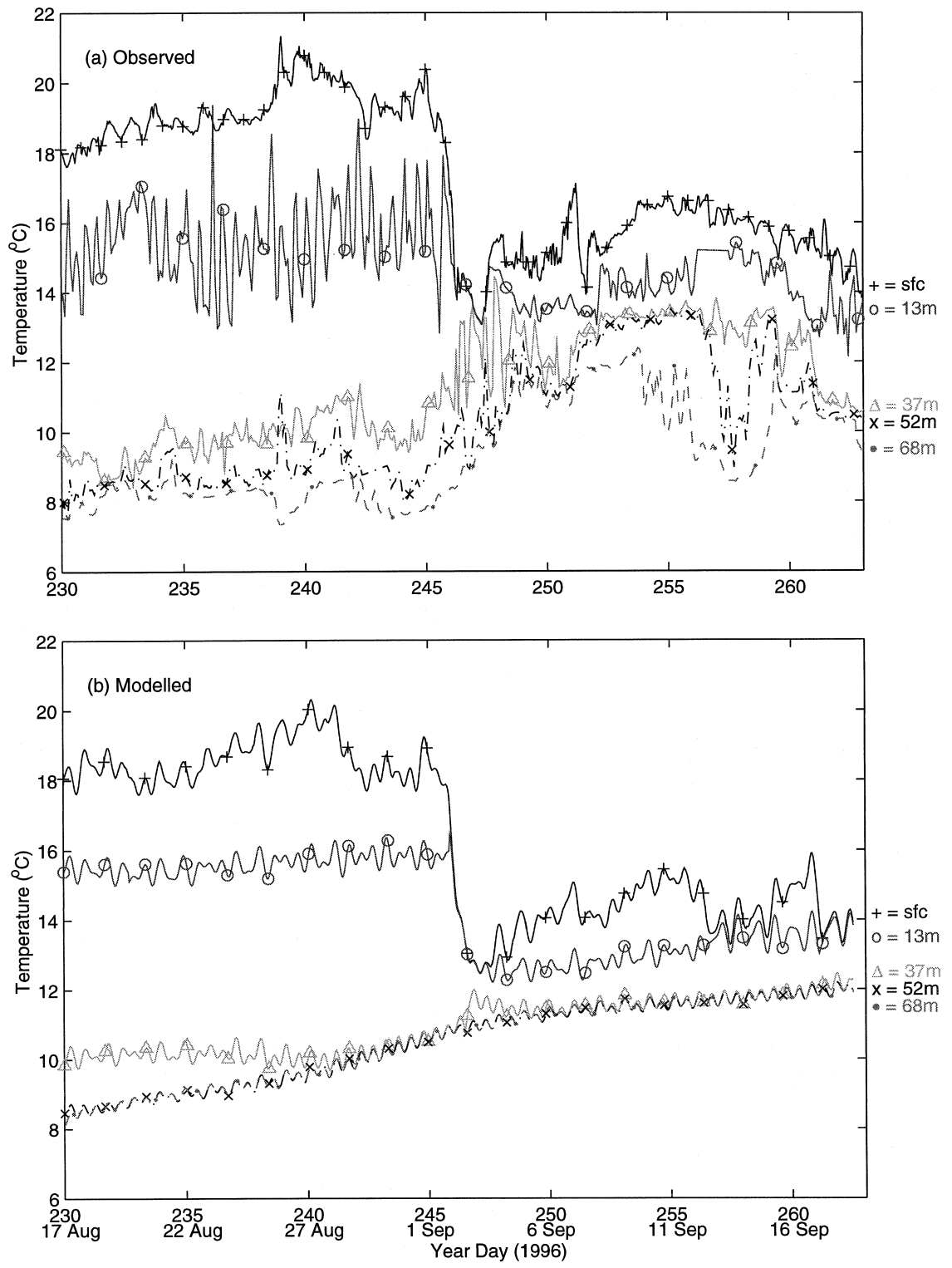

Figure 4. Time series of water-column temperature (a) observations and (b) model-derived; (crosses) surface, (open circles) $13 \mathrm{~m}$, (triangles) $37 \mathrm{~m},\left(X^{\prime} \mathrm{s}\right) 52 \mathrm{~m}$, and (closed circles) $68 \mathrm{~m}$.

of the vertical diffusion (Lick et al., 1993; McNeil et al., 1996; Hill et al., 2001). It could also be due to the fact that the model does not include primary productivity, eliminating biogenic particles as a source of SPM near the surface. Another related difference is seen in the asymmetry of the increases and decreases in SPM as Edouard passes near the CMO 

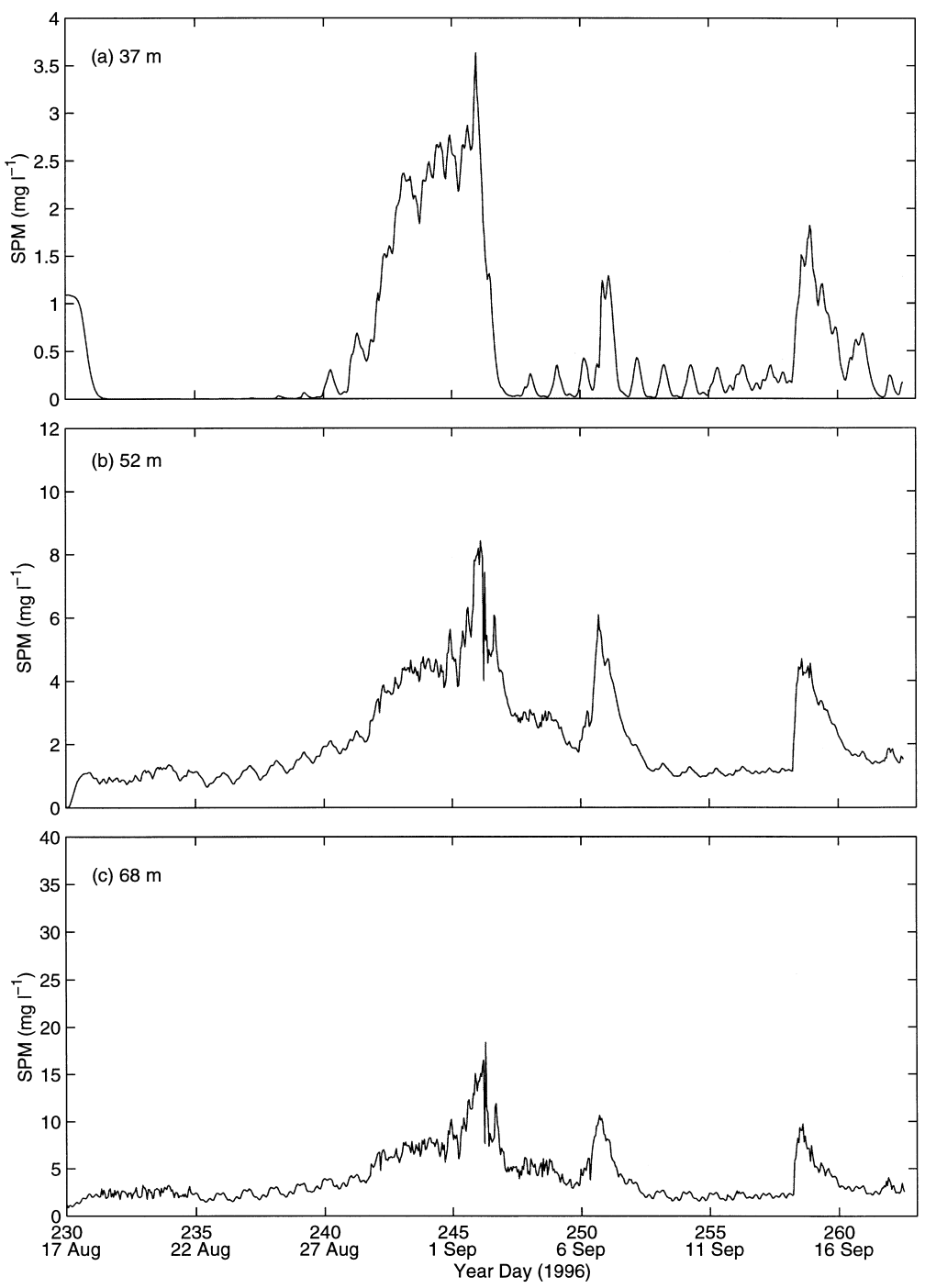

Figure 5. Simulated SPM at (a) $37 \mathrm{~m}$, (b) $52 \mathrm{~m}$, and (c) and $68 \mathrm{~m}$ depth.

site. The rise is gradual for the model and rapid for the observations and vice versa for the decline of SPM. Again, parameterization of de-flocculation could possibly improve the agreement. It is interesting to note that the asymmetric rise and decline of SPM during Hortense is qualitatively consistent for the model and observations. Finally, it should also be noted that there are quantitative differences between peak SPM values during resuspension events. This is not unexpected because of the considerable complexity of modeling SPM (e.g., accounting for the break up of flocculates, sediment size distribution and concentration, etc.). It is possible that the properties of bottom sedimentary materials 

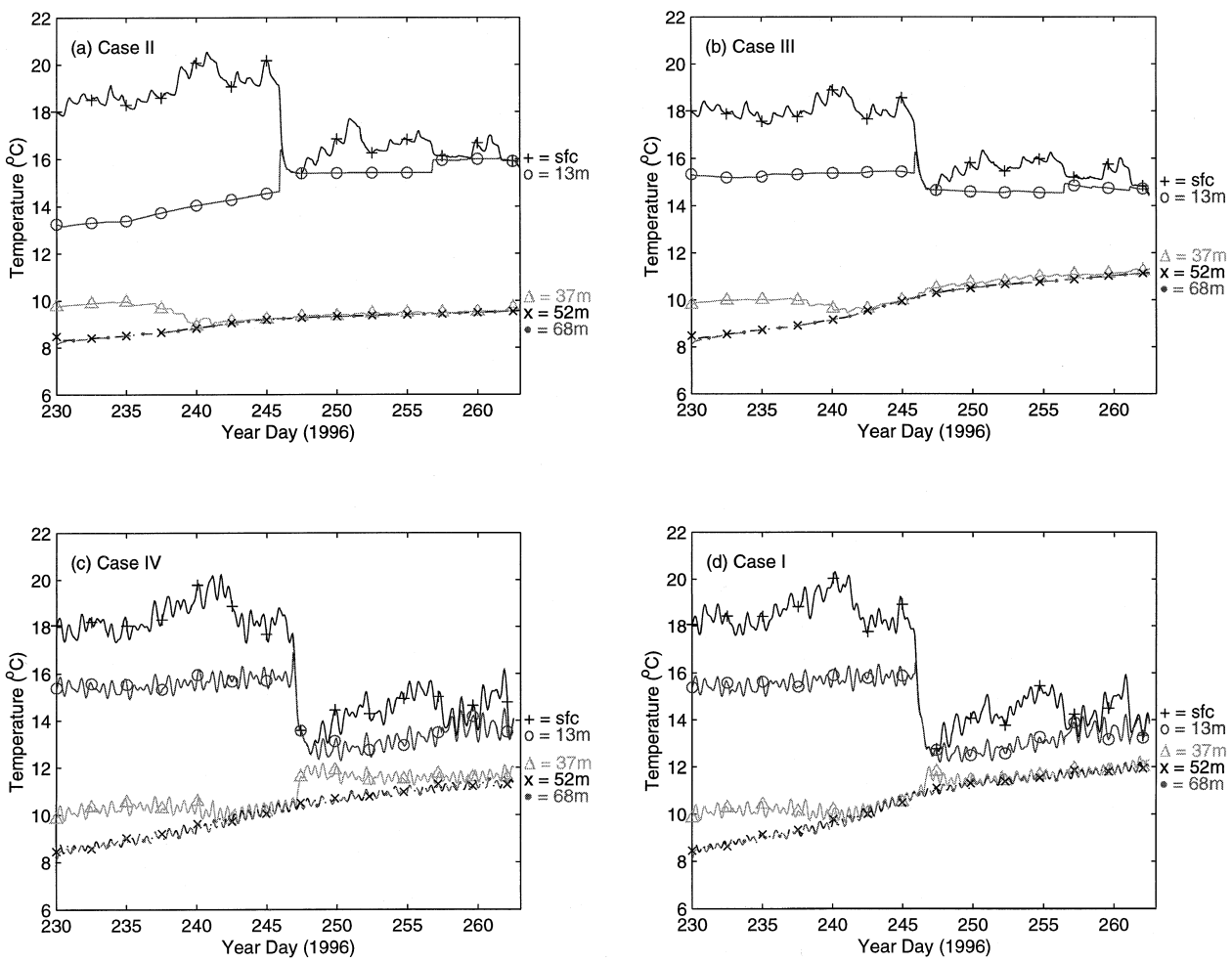

Figure 6. Sensitivity analyses for temperature processes: (a) Case II: simplest simulation including surface heating, wind stress, and tidal forcing, (b) Case III: simulation with heating, wind stress, tidal forcing, and wave-current interaction bottom stress, (c) Case IV: simulation with heating, wind stress, tidal forcing, and horizontal temperature gradients and (d) Case I: full simulation including surface heating, wind stress, tidal forcing, horizontal temperature gradients, and wave-current interaction bottom stress.

change significantly during and following a storm or hurricane (Hill et al., 2001). These changes can lead to the asymmetric rise and decline of SPM and the time lags observed for peaks in resuspension between mooring depths during Edouard and Hortense. It is speculated that during a hurricane, relatively coarse and cohesive matter may be resuspended and broken down into finer sizes (de-flocculation). This would result in reduced settling velocities, allowing particles to remain in suspension for a longer time period. It is also possible that upon settling, these materials may be more easily resuspended through tidal current and/or wind-wave processes. The extreme case would be the consecutive passages of two hurricanes as described in this report. There is insufficient data to test these ideas for the present study.

The results of the model sensitivity simulations of temperature are shown in the four panels of Figure 6: (a) Case II, (b) Case III, (c) Case IV, and (d) Case I. Not surprisingly, Case I best replicates the actual temperature time series data (see Fig. 4). The Case II 
simulation (Fig. 6a) shows the clear effect of wind-mixing produced by Hurricane Edouard that is reflected in the cooling of more than $2^{\circ} \mathrm{C}$ of the surface temperature. It is interesting that the addition of the wave-current interaction effect for Case III (Fig. 6b) only modified the original results slightly by increasing the bottom mixing. This resulted in increased warming of the lower $20 \mathrm{~m}$ of the water column while the surface temperatures are almost unaffected. The Case IV simulation includes the advective-temperature gradient effect, but not the wave-current interaction (Fig. 6c). This simulation produces temperature structure that is quite similar to the full model simulation of Case I (Fig. 6d). Subtle differences include slightly warmer temperatures at $37 \mathrm{~m}$ and a thicker bottom mixed layer than for Case I following Hurricane Edouard. This last intercomparison of Case I and IV simulations suggests that the most important processes controlling the thermal water column structure for Hurricane Edouard are the wind stirring and to a lesser extent the advective-temperature gradient process.

Based on energy arguments, the potential energy anomaly (see Appendix III for formulation) is used as a measure of stratification. In this work it will be used as a tool to assess the importance of different physical processes controlling the water column thermal structure. The computations of the observed potential energy anomaly, $\phi$, uses relatively coarse temporal resolution ship-based temperature profile data collected by W. S. Pegau and E. Boss (Oregon State University) within $100 \mathrm{~m}$ of the CMO mooring. This choice was made because of the need for higher vertical resolution data $(\sim 1 \mathrm{~m})$ than could be obtained with our fixed-depth mooring temperature sensors. The time series of potential energy anomaly data (observed and modeled) are shown in Figure 7. Prior to the passage of Hurricane Edouard, the simulated values of potential energy anomaly are very similar for all Cases. However, the simulations overestimate the observed potential energy anomaly by $\sim 20 \mathrm{~J} \mathrm{~m}^{-3}$ on average. Also, considerable variability is evident in the observations. This variability is likely caused by internal tides and gravity waves, processes not represented in the model. Ship-based measurements were not possible during the hurricane. However, measurements resumed a few days afterward and were once again variable, again probably because of internal tides and internal waves. The model simulation for Case I was in good agreement, though somewhat overestimating observed potential energy anomaly following the passage of Edouard. The Case II simulation, which included heating, winds, and tides, but not wave nor advective effects, was the poorest of the simulations (overestimates $\phi$ by roughly $60 \mathrm{~J} \mathrm{~m}^{-3}$ ). The Case III and IV simulation results were also quite poor (overestimates $\phi$ by roughly $40 \mathrm{~J} \mathrm{~m}^{-3}$ ). The results suggest that the wave-current and advection forcing are of nearly equal importance and both must be included in similar models of stratification.

The final analysis concerns the relative effects on resuspension as indicated by SPM (Figs. 8 and 9). Sensitivity analyses were performed using Cases I-IV (as before) for SPM with results shown in Figure 8. The Case II and IV simulations produced relatively little resuspension $\left(\sim 1 \mathrm{mg} \mathrm{l}^{-1}\right)$ and there was no clear effect of the hurricanes (Fig. 8a and 8c). However, when wave-current interaction was included (Case III), the resuspension 


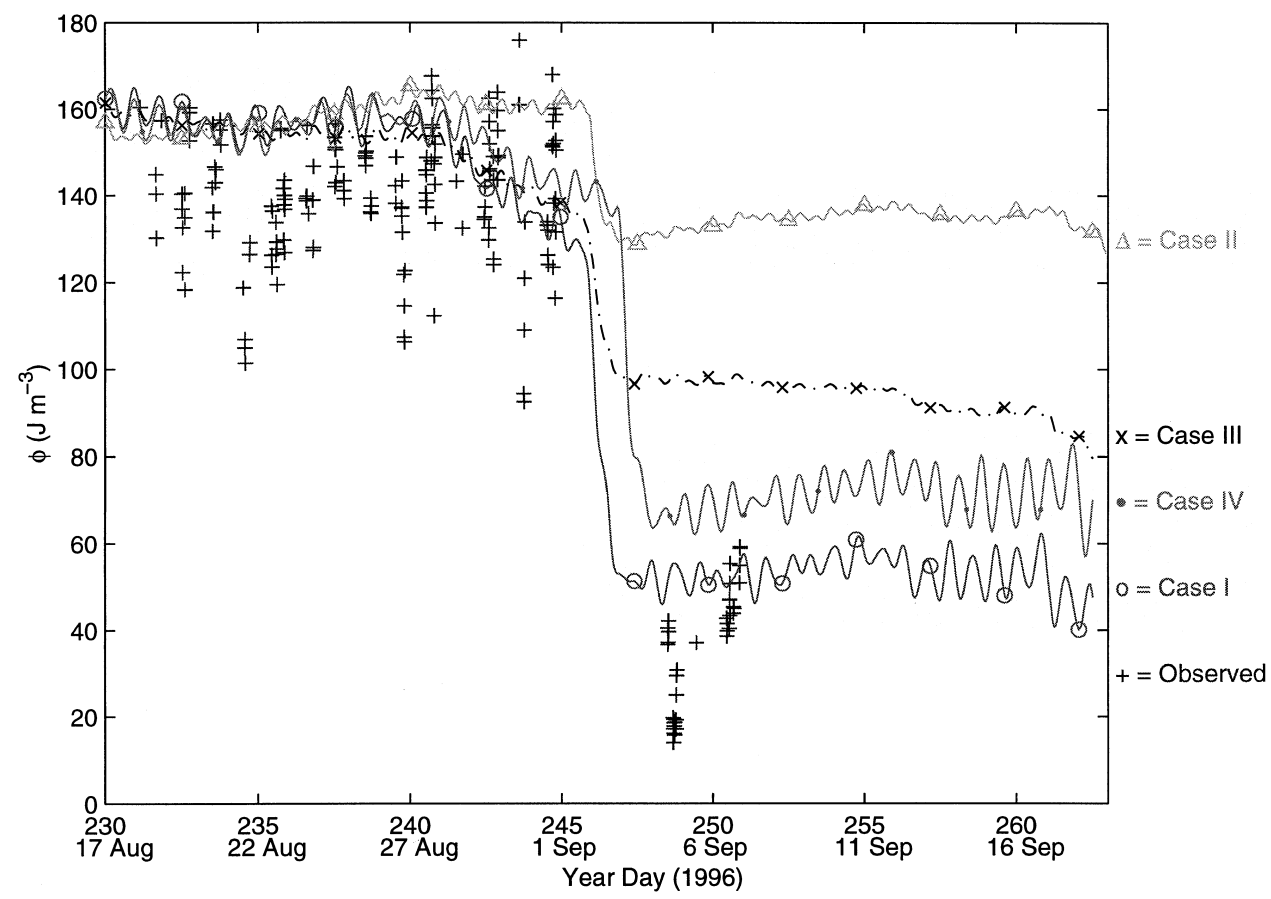

Figure 7. Potential energy anomaly time series of (crosses) CTD data collected near the CMO mooring, Case I (open circles) full simulation (same as in Fig. 6), Case IV (closed circles), Case III $\left(X^{\prime}\right.$ 's), and Case II (triangles).

increased with near-bottom concentrations of $\sim 18 \mathrm{mg} \mathrm{l}^{-1}$ during Edouard. There is a clear effect of the hurricane-generated waves around day 246 and day 259 (Fig. 8b). There is little difference between Case III and Case I; the dominant process is clearly the wave-current effect. It should be emphasized that for these simulations there was no provision for the advection of sediments. Figure 9 shows that the bottom stress due the wave-current interaction $\left(\tau_{w+c}\right.$; Fig. 9b) was over an order of magnitude larger than the current-only bottom stress $\left(\tau_{c}\right.$; Fig. 9a) during the passages of Hurricanes Edouard and Hortense. These time series strongly indicate that the resuspension during strong wind and high wave conditions is due to wave-current interaction. Tidal currents are likely important under less intense forcing. Grant and Madsen (1979), Wright et al. (1986), Glenn and Grant (1987), Lyne et al. (1990), and many others have shown that sediment resuspension in the presence of waves without strong subtidal currents is not uncommon. Dickey et al. (1998) and Chang et al. (2001) used CMO bottom current and beam $c$ data and the model presented in Christoffersen and Jonsson (1985) to show that sediment resuspension during Hurricanes Edouard and Hortense was primarily driven by near bottom wave-current processes. 

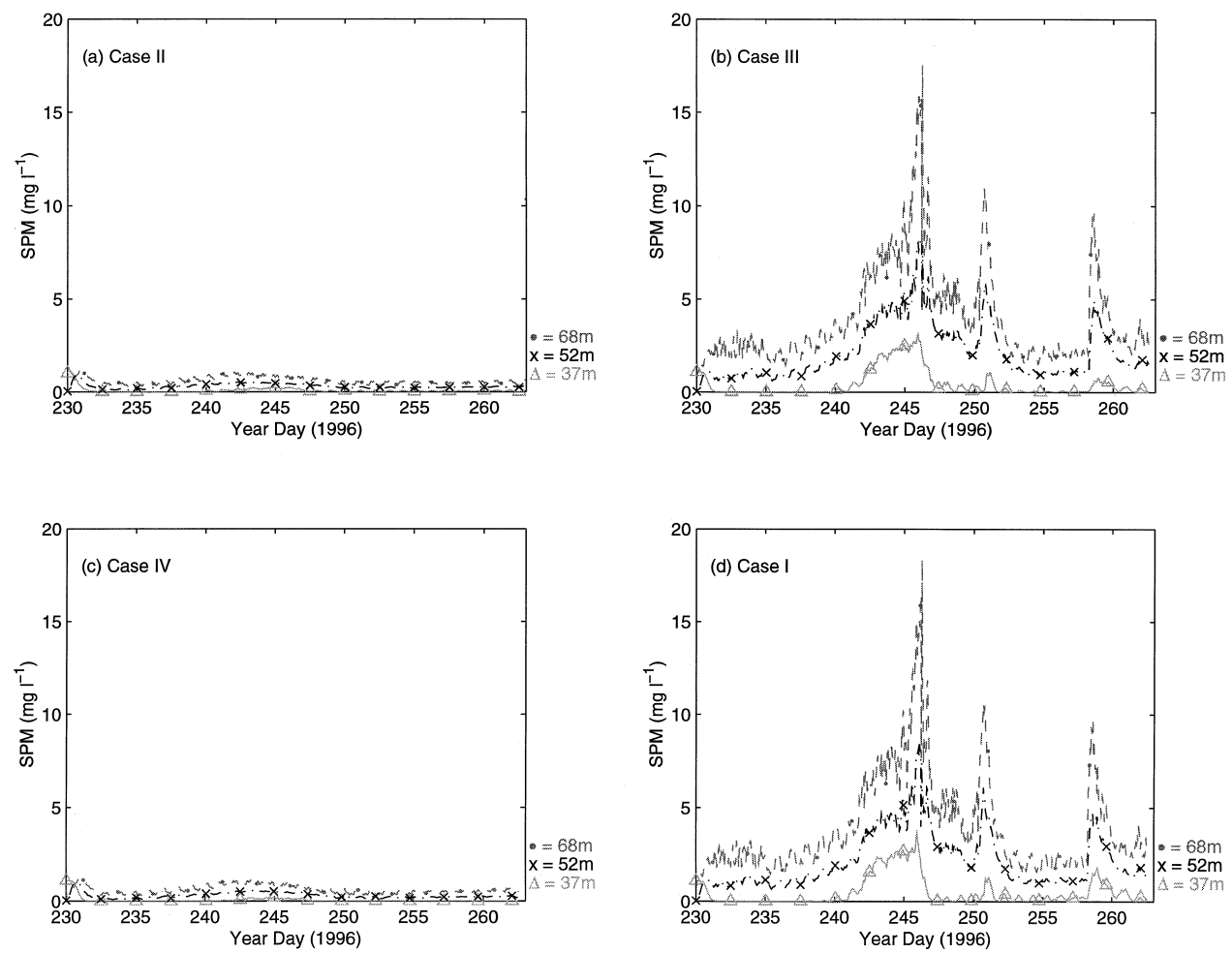

Figure 8. The same as Figure 6 but for SPM at (triangles) $37 \mathrm{~m}$, (×'s) $52 \mathrm{~m}$, and (closed circles) $68 \mathrm{~m}$.

\section{Summary and conclusions}

The present study uses a numerical model to examine processes that contributed to the evolution of thermal structure and resuspension of particulate matter during and after the passages of two hurricanes. The model's initial and boundary conditions were obtained from high resolution physical and optical time series observations collected at a mooring site on the Middle Atlantic Bight continental shelf ( $70 \mathrm{~m}$ water depth) in the late summer of 1996. Fortuitously, the eyes of Hurricanes Edouard and Hortense passed within 110 and $350 \mathrm{~km}$ of the site, respectively, within about two weeks.

The physical model used for the study accounted for wind and bottom current-generated turbulence, wave-current interactions, tides, and depth-dependent density driven circulation. Four different case study simulations were performed. The most important process controlling the thermal water column structure for Hurricane Edouard was the wind stirring. Bottom wave mixing and induced advection played secondary roles. Differences between the model results and the observations in the bottom layer may have been caused by inflow of warm shelf water, which may have been advected by the downwelling favorable winds. There was also clear evidence of internal tides in the observations, 

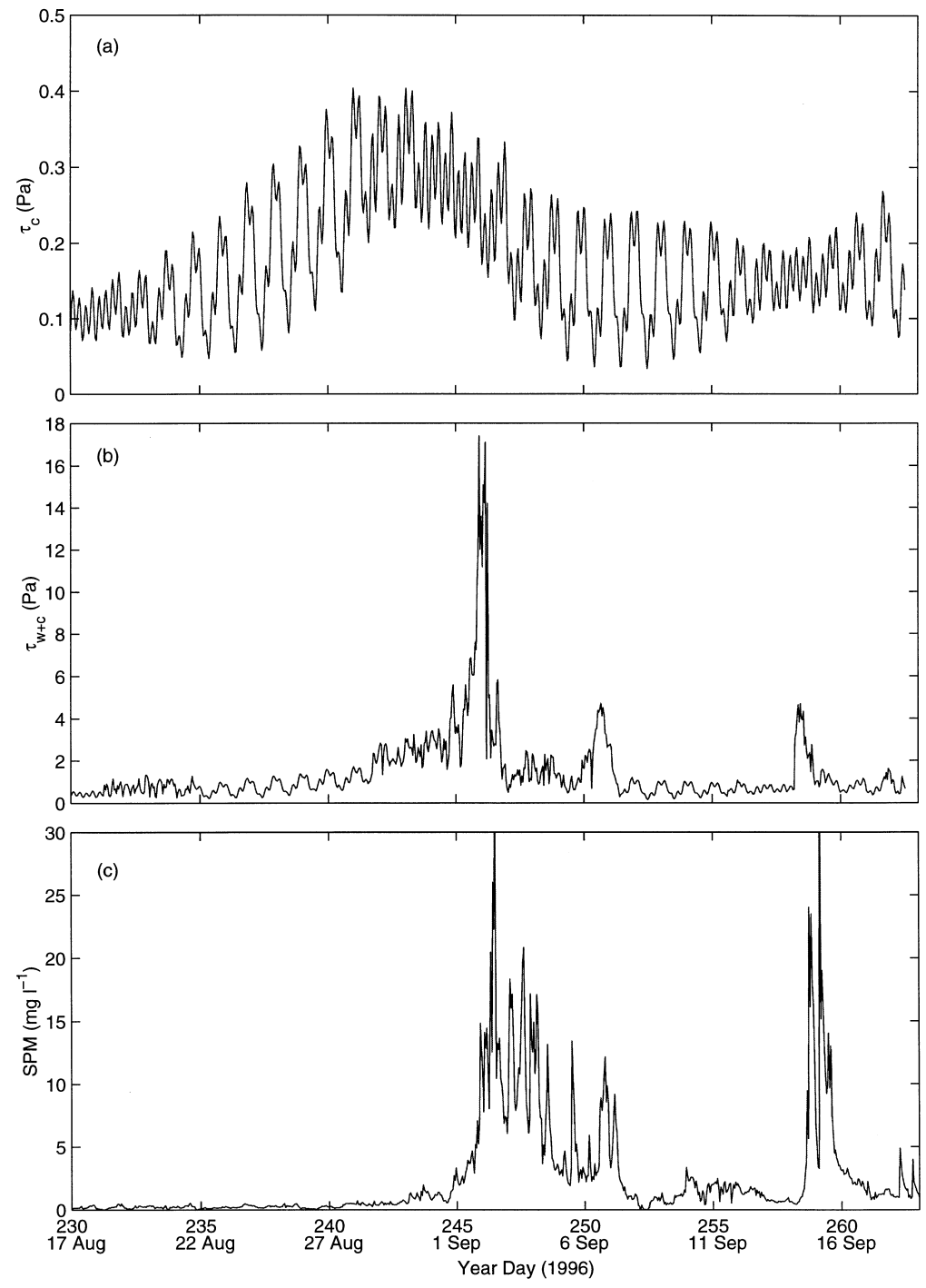

Figure 9. Model simulation results for (a) current bottom stress, (b) wave-current combined bottom stress; and (c) observed SPM at $68 \mathrm{~m}$.

whereas the model, being one-dimensional, could not reproduce this effect. Finally, another analysis, which uses computations of the potential density anomaly, indicated that all forcing mechanisms must to be included to produce results in general agreement with data.

A suspended particulate matter (SPM) model was included as a module of the physical model to examine sediment resuspension processes. Simulations show that wave-current 
bottom stress is clearly the most important process for sediment resuspension during and following hurricanes.

Our results indicate that the primary features of the observations, including water column thermal structure and the timing of the sediment resuspension events, were reasonably well represented by the one-dimensional physics of the model. It is important to note that the results from our model, which is based on first principles, show that the observations and hypotheses of Chang et al. (2001) were indeed correct in that sediment resuspension observed at the CMO site during Hurricane Edouard and Hortense was primarily forced by near bottom wave-current processes. Improved understanding will require three-dimensional observations and models of physics and SPM, the latter with a formulation for flocculation and de-flocculation.

Acknowledgments. The modeling part of this work was supported by a POL internal grant on mixing and sediment resuspension on shelf seas. The observational part of this work was supported by the Office of Naval Research as part of the Coastal Mixing and Optics program (T.D.D. Grant No. N00014-96-1-0669). We thank Steve Lentz and Steve Anderson for allowing us to use their sea-surface temperature, wave, and meteorological data, Andrew Barnard for sharing the CTD data, and Wilf Gardner for his beam c/SPM relationships. We would also like to thank Rich Signell for helping us to find the tidal data needed to force the model and to Emmanuel Boss for his comments on an earlier version of this manuscript. A. J. Souza would also like to thank Carlos Lozano for first calling attention to the $\mathrm{CMO}$ data and for encouraging him to produce the model.

\section{APPENDIX I}

\section{Conversion of Beam $c$ to SPM}

Beam $c$ and suspended particulate matter (SPM) calibration relations were obtained by Gardner et al. (2001) using linear regressions of ship-based profile data (from bottle samples for SPM $\left(\mathrm{mg} \mathrm{l}^{-1}\right)$ and profiled beam transmissometer data for beam $c$ ) at our site. These relationships were used to transform our time series of beam $c$ (as observed using the mooring and bottom tripod) to time series of SPM. In order to optimize the correlation coefficients of the regressions, the data were subdivided into the following categories: (1) near-surface data collected prior to Hurricane Edouard, (2) near-bottom data collected prior to Edouard, (3) near-surface data collected after passage of Edouard, and (4) near-bottom data collected after passage of Edouard. The four conversion equations are:

$$
\begin{gathered}
\mathrm{SPM}=1.0 \text { beam } c-0.169 \text { Surface layer before Hurricane Edouard } \\
\mathrm{SPM}=1.1 \text { beam } c-0.088 \text { Bottom layer before Hurricane Edouard } \\
\mathrm{SPM}=0.77 \text { beam } c-5.4 \times 10^{-3} \quad \text { Surface layer after Hurricane Edouard } \\
\mathrm{SPM}=2.5 \text { beam } c-1.08 \text { Bottom layer after Hurricane Edouard }
\end{gathered}
$$




\section{APPENDIX II}

\section{Model formulations}

\section{Hydrodynamical model}

The hydrodynamical model is one-dimensional and follows that of Souza and Simpson (1997). The numerical model uses an explicit scheme to integrate the equations of motion:

$$
\begin{aligned}
& \frac{\partial u}{\partial t}=-\frac{1}{\rho} \frac{\partial P}{\partial x}+f v+\frac{\partial}{\partial z}\left(N_{z} \frac{\partial u}{\partial z}\right) \\
& \frac{\partial v}{\partial t}=-\frac{1}{\rho} \frac{\partial P}{\partial y}-f u+\frac{\partial}{\partial z}\left(N_{z} \frac{\partial v}{\partial z}\right)
\end{aligned}
$$

where horizontal position (velocity) coordinates $x(u)$ and $y(v)$ are positive in the east and north directions, the vertical coordinate $z$ is defined to be positively upward from the seabed, $P$ is pressure, $\rho$ is density, $f$ is the local Coriolis parameter (twice the earth rotation rate times the sine of the local latitude), and $N_{z}$ is the coefficient of vertical eddy viscosity. The terms on the left-hand side of Eqs. $2 \mathrm{a}$ and $2 \mathrm{~b}$ represent local acceleration; the first terms on the right-hand side are horizontal pressure gradients, the following terms are the Coriolis accelerations, and the final terms account for the effects of turbulence acting between the model's vertical layers resulting in vertical transport of momentum. The $x$ and $y$-components (along-shelf and cross-shelf, respectively) of the pressure gradient terms in Eq. 2 can be expressed as:

$$
\begin{aligned}
& \frac{1}{\rho} \frac{\partial P}{\partial x}=g\left(\frac{\partial \eta}{\partial x}\right)_{\text {tidal }}+g \frac{\partial \bar{\eta}}{\partial x}+\frac{g}{\rho}(h-z) \frac{\partial \rho}{\partial x} \\
& \frac{1}{\rho} \frac{\partial P}{\partial y}=g\left(\frac{\partial \eta}{\partial y}\right)_{\text {tidal }}+g \frac{\partial \bar{\eta}}{\partial y}+\frac{g}{\rho}(h-z) \frac{\partial \rho}{\partial y}
\end{aligned}
$$

where $g$ is the acceleration due to gravity, $h$ is the mean water depth, $\eta$ is the instantaneous surface displacement, $z$ is the vertical coordinate with $z=0$ at the seabed and $z=h+\eta$ at the sea surface. The first term on the right on Eq. 3 is a tidally oscillating sea-surface slope. The second two terms represent the effect of a depth-invariant horizontal density gradient setting up a mean surface slope and driving a depth dependant circulation. Calculations of the mean surface slope are achieved by specifying a zero net flow condition in the cross-shelf direction, in such way that

$$
\frac{\partial \bar{\eta}}{\partial y}=\gamma \frac{h}{\rho} \frac{\partial \rho}{\partial y}
$$

where the parameter $\gamma$ is chosen to make the net cross-shelf transport equal zero (Heaps, 1972).

The tidal slopes are calculated using tidal harmonics for $O_{1}, K_{1}, M_{2}, N_{2}$, and $S_{2}$ 
(Luettich and Westerink, 1995). The depth-invariant horizontal density gradient is calculated assuming that the alongshelf temperature gradient $\partial T / \partial x$ was zero and the cross-shelf gradient was constant with a value of $\partial T / \partial y=0.8^{\circ} \mathrm{C} / 10 \mathrm{~km}$ in setting up a mean surface slope. This was calculated from a CTD section on YD 230.

The bottom boundary conditions for the momentum equations include modification of the bottom stress due to wave-current interaction; this is similar to one used by Davies and Lawrence (1995). The combined shear stress $\tau_{T}$ resulting from currents, $\tau_{c}$, and waves, $\tau_{w}$, which is the case of a co-linear flow, is given by:

$$
\tau_{T}=\tau_{C}+\tau_{W}
$$

with

$$
\tau_{C}=\frac{1}{2} f_{C} \rho U_{b}^{2}
$$

and

$$
\tau_{W}=\frac{1}{2} f_{W} \rho U_{0}^{2}
$$

where $U_{0}$ is the maximum near-bed wave orbital velocity, $U_{b}$ is the bottom current speed, $\rho$ is again the water density, and $f_{w}$ and $f_{c}$ are the friction factors for waves and currents, respectively. In the common case when the bottom stress is calculated only from currents and with a constant drag coefficient $1 / 2 f c=C_{D}=0.003$.

The near-bed orbital velocity is given by:

$$
U_{0}=\frac{a_{w} \omega}{\sinh k h}
$$

where $a_{w}$ as the wave amplitude, $\omega$ is the wave frequency, and $k$ as the wavenumber. The wave dispersion relation is:

$$
\omega^{2}=g k \tanh k h
$$

The wave friction factor $f_{w}$ is calculated using empirical expressions from Grant and Madsen (1982) or

$$
f_{w}= \begin{cases}0.13\left(\frac{k_{b}}{A_{b}}\right)^{0.4} & \frac{k_{b}}{A_{b}}<0.08 \\ 0.23\left(\frac{k_{b}}{A_{b}}\right) & 0.08 \leq \frac{k_{b}}{A_{b}}<1.00 \\ 0.23 & \frac{k_{b}}{A_{b}} \geq 1.00\end{cases}
$$

where $k_{b}=30 * z_{0}, z_{0}$ is the roughness length, and $A_{b}=U_{0} / T$, with $T=2 \pi / \omega$. 
The calculation of the effective drag coefficient or current friction factor, $f_{c}$, follows the formulation of Davies and Lawrence (1995) and takes into account wave effects. It is assumed that the current does not influence the wave field. The wave friction velocity is given by:

$$
U_{* w}=\left(\frac{\tau_{w}}{\rho}\right)^{1 / 2} .
$$

The initial condition for the current factor, $f_{c}$, excluding wind-wave turbulence, is determined using the formula:

$$
f_{c}=2\left[\frac{\kappa}{\ln \left(30 z_{r} / k_{b c}\right)}\right]^{2}
$$

where $\mathrm{\kappa}$ is the von Karman's constant, $k_{b c}=k_{b}$ for the initial calculation, and $z_{r}$ the reference height at which the slip condition is applied.

Once $f_{c}$ is calculated, $U_{*_{c}}$ can be computed from

$$
U_{* c}=\left(\frac{\tau_{c}}{\rho}\right)^{1 / 2}
$$

with $U_{* c}$ having components $\left(U_{* c x}, U_{* c y}\right)$.

The combined friction velocity $U_{* c w}$ for waves and currents is then given by

$$
U_{* c w}=\left(U_{*_{c}}^{2}+U_{*_{w}}^{2}\right)^{1 / 2} .
$$

The apparent roughness $k_{b c}$ felt by the current due to the presence of surface waves is given by:

$$
k_{b c}=k_{b}\left[C_{1} \frac{U_{* c w}}{U_{* w}} \frac{A_{b}}{k_{b}}\right]^{\beta}
$$

with $C_{1}=24.0$ (Grant and Madsen, 1979) and

$$
\beta=1-\frac{U_{* c}}{U_{* c w}} .
$$

The value of $k_{b c}$ is used to calculate $f_{c}$ at the next time step and then to calculate the total shear stress $\tau_{T}$. This is the standard procedure as used by Davies and Lawrence (1995) and Signell and List (1997). The significant wave height and wave period were obtained from the wave rider and NDBC buoys as explained earlier. The components of the bed shear stress were approximated as:

$$
\tau_{T}(x, y)=\rho U_{* c w} U_{* c x}, U_{* c y} .
$$


The surface wind stress was determined using the wind data from the meteorological buoy as:

$$
\tau_{s}(x, y)=-C_{D 0} \rho_{a}\left(u_{w}^{2}+v_{w}^{2}\right)^{1 / 2} u_{w}, v_{w}
$$

where $u_{w}$ and $v_{w}$ are the $x$ and $y$ components of surface wind velocity, $\rho_{a}=1.3 \mathrm{~kg} \mathrm{~m}^{-3}$ is the air density and $C_{D 0}=(0.75+0.067 *$ wind speed $) \times 10^{-3}$ is the surface drag coefficient as a function of wind speed (Garratt, 1977).

The heat balance equation used for the model includes horizontal advection and vertical turbulent diffusion of temperature at each vertical level and is given by

$$
\frac{\partial T}{\partial t}=-v \frac{\partial T}{\partial y}+\frac{\partial}{\partial z}\left(K_{z} \frac{\partial T}{\partial z}\right)
$$

where $\partial T / \partial t$ is the local temperature or tendency term, $v$ is again the northward component of velocity calculated by the model, $\partial T / \partial y$ is the cross-shelf horizontal temperature gradient $(\partial T / \partial y$ is assumed depth independent; note that the alongshelf temperature gradient $\partial T / \partial x$ is assumed to be zero), and $K_{z}$ is the coefficient of vertical eddy diffusivity with no heat flux through the seabed. Finally, surface heat fluxes are specified using meteorological observations of solar radiation, air temperature, relative humidity, and wind speed and empirical relations for the heat fluxes given by Gill (1982).

The Mellor-Yamada level 2.5 turbulence closure scheme is used to calculate vertical profiles of vertical viscosity $N_{z}$, vertical diffusivity $K_{z}$, and the turbulence parameter $N_{q}$ according to:

$$
\begin{gathered}
N_{z}=S_{M} l q \\
K_{z}=S_{H} l q \\
N_{q}=0.2 l q
\end{gathered}
$$

where $q^{2}$ is twice the turbulent kinetic energy, $l$ is a mixing length (Simpson and Sharples, 1992) and $S_{M}$ and $S_{H}$ are stability functions, which depend on the local gradient Richardson number (for details, see Mellor and Yamada, 1974).

As discussed earlier, the model was initialised using temperature and salinity and SPM values from a CTD cast taken at the mooring site on YD 230. The model then was run for five days to stabilise currents and turbulence before being reinitialised with the same CTD cast and the appropriate tidal and meteorological data.

The model was integrated with a vertical resolution of $2 \mathrm{~m}$ and a time step of 2 seconds which satisfies the stability condition:

$$
\Delta t<\frac{1}{2} \frac{(\Delta z)^{2}}{N_{z}}
$$




\section{The SPM model}

The SPM model is based upon an earlier model developed by Jones et al. (1996). The model assumes the presence of two settling velocities. The generalised diffusiondeposition equation for two different particle types is:

$$
\frac{\partial C_{i}}{\partial t}=\frac{\partial}{\partial z}\left(K_{z} \frac{\partial C_{i}}{\partial z}\right)+W_{s i} \frac{\partial C_{i}}{\partial z}
$$

where $C_{i}$ is the particle concentration with $i=1,2$ for the two different size classes, $K_{z}$ is the same eddy viscosity used for temperature (see above) as calculated by the turbulence closure scheme, and $W_{s i}$ is the settling velocity for the two size classes $i=1,2$. The left-hand side indicates the local or tendency term, the first term on the right represents the vertical diffusion of particles via turbulence, and the final term on the right represents the vertical advection of particles under settling conditions. The aim of this work was to assess the wave resuspension effect, therefore the horizontal advection of particles was neglected. For the present study, it was found that values of $W_{s 1}=0.5 \mathrm{~cm} \mathrm{~s}^{-1}$ and $W_{s 2}=$ $0.005 \mathrm{~cm} \mathrm{~s}^{-1}$ best fitted the observations. A zero net flux boundary condition was imposed at the sea surface. The seabed fluxes due to entrainment and deposition were formulated by using the following equation:

$$
-W_{s i} C_{i}-K_{z} \frac{\partial C}{\partial z}=E-W_{d i} C_{i}
$$

where $E$ is the entrainment rate (in $\mathrm{gm}^{-2} \mathrm{~s}^{-1}$ ) and $W_{d i}$ is the "deposition velocity," assumed to be the same as the settling rate (Lavelle et al., 1984). The estimation of the entrainment rate must be done empirically; thus, we assumed a simple function of the bed shear stress that has been successful in reproducing resuspension in European shelf seas. The entrainment rate is given by:

$$
E=\alpha_{s}\left|\tau_{T}\right|^{n}
$$

where $\alpha_{s}$ and $n$ (in this case chosen to be $10^{-6}$ and 1 , respectively, chosen after tuning the model) are adjustable parameters and $\tau_{T}$ is calculated using equations above. The total SPM concentration was then calculated as the sum of the two individual particle sizes at each vertical interval.

\section{APPENDIX III}

\section{Calculation of potential energy anomaly}

The potential energy anomaly is generally used as a measurement of stratification, as it represents the amount of energy needed to mix the water column (Simpson and Bowers, 1981). In this particular case it is used as a tool to assess the effect that different processes have in controlling the water column stability. The potential energy anomaly is evaluated using the following relationship 


$$
\phi=\frac{1}{h} \int_{0}^{h}(\bar{\rho}-\rho) g z d z ; \quad \bar{\rho}=\frac{1}{h} \int_{0}^{h} \rho d z
$$

where $h$ is water depth, $g$ is the acceleration of gravity, and $\rho$ is water density.

\section{REFERENCES}

Agrawal, Y. C. and P. Traykovski. 2001. Particles in the bottom boundary layer: Size dynamics through events. J. Geophys. Res., 106, 9533-9542.

Backus, R. H. 1987. Georges Bank, MIT Press, Cambridge, MA, 593 pp.

Brink, K. H., B. A. Magnell and M. A. Noble. 1987. Low-frequency current and bottom-pressure variability, in Georges Bank, R. G. Backus, ed., MIT Press, Cambridge, MA, 140-146.

Brown, W. S. and J. A. Moody. 1987. Tides, in Georges Bank, R. G. Backus, ed., MIT Press, Cambridge, MA, 100-107.

Chang, G. C. and T. D. Dickey. 2001. Optical and physical variability on timescales from minutes to the seasonal cycle on the New England shelf: July 1996-June 1997. J. Geophys. Res., 106, 9435-9454.

Chang, G. C., T. D. Dickey and A. J. Williams, III. 2001. Sediment resuspension over a continental shelf during Hurricanes Edouard and Hortense. J. Geophys. Res., 106, 9517-9531.

Christoffersen, J. B. and I. G. Jonsson. 1985. Bed friction and dissipation in a combined current and wave motion. Ocean Eng., 12, 387-423.

Davies, A. M. and J. Lawrence. 1995. Modeling the effect of wave-current interaction on the three-dimensional wind-driven circulation of the eastern Irish Sea. J. Phys. Oceanogr., 25, 29-45.

Dickey, T. D., G. C. Chang, Y. C. Agrawal, A. J. Williams, III and P. S. Hill. 1998. Sediment resuspension in the wakes of Hurricanes Edouard and Hortense. Geophys. Res. Lett., 25, 3533-3536.

Dickey, T. D. and A. J. Williams III. 2001. Interdisciplinary ocean process studies on the New England shelf. J. Geophys. Res., 106, 9427-9434.

Eisma, D. 1990. Transport and deposition of suspended matter in the North Sea and the relation to coastal siltation, pollution and bottom fauna distribution, Rev. Aquatic Sci., 3, 181-216.

Galbraith, N., A. Pluddemann, S. Lentz, S. Anderson, M. Baumgartner and J. Edson. 1999. Coastal mixing and optics experiment: moored array data report, WHOI-99-15 Rep, $92 \mathrm{pp}$.

Gardner, W. D., J. C. Blakey, I. D. Walsh, M. J. Richardson, S. Pegau, J. R. V. Zaneveld, C. Roesler, M. C. Gregg, J. A. MacKinnon, H. M. Sosik and A. J. Williams III. 2001. Optics, particles, stratification, and storms on the New England continental shelf. J. Geophys. Res., 106, 9473-9497.

Garratt, J. R. 1977. Review of drag coefficients over oceans and continents. Mon. Weath. Rev., 105, 915-929.

Gill, A. E. 1982. Atmosphere-Ocean Dynamics, Academic Press, San Diego, CA, 662 pp.

Glenn, S. M. and W. D. Grant. 1987. A suspended sediment stratification correction for combined wave and current flows. J. Geophys. Res., 92, 8244-8264.

Grant, W. D. and O. S. Madsen. 1979. Combined wave and current interaction with a rough bottom. J. Geophys. Res., 84, 1797-1808.

1982. Movable bed roughness in unsteady oscillatory flow. J. Geophys. Res., 87, 469-481.

Hill, P. S., G. Voulgaris and J. H. Trowbridge. 2001. Controls on floc size in a continental shelf bottom boundary layer. J. Geophys. Res., 106, 9543-9549.

Jones, S. E., C. F. Jago and J. H. Simpson. 1996. Modelling suspended sediment dynamics in tidally stirred and periodically stratified waters: progress and pitfalls, in Mixing in Estuaries and Coastal Seas, C. Pattiaratchi, ed., Coastal and Estuarine Studies, 50, Amer. Geophys. Union, Washington, DC, 302-324. 
Lavelle, J. W., H. O. Mojfeld and E. T. Baker. 1984. An in situ erosion rate for fine-grained marine sediment. J. Geophys. Res., 89(C4), 6543-6552.

Lick, W., H. Huang and R. Jepsen. 1993. Flocculation of fine-grained sediments due to differential settling. J. Geophys. Res., 98, 10,279-10,288.

Luettich, R. A., Jr. and J. J. Westerink. 1995. Continental shelf scale convergence studies with a barotropic tidal model, in Quantitative Skill Assessment for Coastal Ocean Models, D. Lynch and A. M. Davies, eds., Coastal and Estuarine Studies, 48, Amer. Geophys. Union, Washington, DC, 349-371.

Lyne, V. D., B. Butman and W. D. Grant. 1990. Sediment movement along the U.S. east coast continental shelf: I. Estimates of bottom stress using the Grant-Madsen model and near-bottom wave and current measurements. Cont. Shelf Res., 13, 397-428.

Mellor, G. L. and T. Yamada. 1974. A hierarchy of turbulence closure models for planetary boundary layers. J. Atmos. Sci., 31, 1791-1806.

McNeil, J., C. Taylor and W. Lick. 1996. Measurements of erosion of undisturbed bottom sediments with depth. J. Hydraulic Eng., 122, 316-324.

Signell, R. P. and J. H. List. 1997. Effect of wave-enhanced bottom friction on storm-drive circulation in Massachusetts Bay. J. Waterway, Port, Coast. Ocean Eng., 123, 233-239.

Simpson, J. H. and D. Bowers. 1981. Models of stratification and frontal movement in the shelf seas. Deep-Sea Res., 28, 727-738.

-1984. The role of tidal stirring in controlling the seasonal heat cycle in shelf areas. Annals. Geophys., 26, 411-416.

Simpson, J. H. and J. Sharples. 1992. Dynamically-active models in prediction of estuarine stratification, in Dynamics and Exchange in Estuaries and the Coastal Zone, D. Prandle, ed., Coastal and Estuarine Studies, 40, Amer. Geophys. Union, Washington, DC, 101-113.

Souza, A. J. and J. H. Simpson. 1997. Controls on stratification in the Rhine ROFI system. J. Mar. Syst., 12, 311-323.

Tett, P. B., I. R. Joint, D. A. Purdie, M. Baars, S. Oosterhuis, G. Daberi, F. Hannah, D. K. Mills, D. Plummer, A. J. Pomroy, A. W. Walne and H. J. Witte. 1993. Biological consequences of tidal stirring gradients in the North Sea. Phil. Trans. Roy. Soc., Series A, 343, 493-508, 1993.

Twichell, D. C., B. Butman and R. S. Lewis. 1987. Shallow structure, surficial geology and processes currently shaping the bank, in Georges Bank, R. H. Backus, ed., MIT Press, Cambridge, MA, 31-38.

Wright, L. D., J. D. Boon III, M. O. Green and J. H. List. 1986. Response of the mid shoreface of the southern Mid-Atlantic Bight to a "Northeaster." Geo-Mar. Lett., 6, 153-160.

Received: 8 August, 2000; revised: 21 June, 2001. 